\title{
Uma Antropologia da Transmissão: mosquitos, mulheres e a epidemia de Zika no Brasil
}

An Anthropology of Transmission: mosquitoes, women, and the Zika epidemic in Brazil

\author{
Luísa Reis-Castro ${ }^{1}$ \\ Carolina de Oliveira Nogueira²
}

${ }^{1}$ Instituto de Tecnologia de Massachusetts (MIT), Cambridge, MA, Estados Unidos

${ }^{2}$ Fundação Oswaldo Cruz, Rio de Janeiro, RJ, Brasil 


\section{Resumo}

No Brasil, o Zika é apresentado como um vírus transmitido somente por mosquitos e sua epidemia é vista como uma preocupação somente para mulheres. Para examinar essa errônea caracterização, este artigo investiga as múltiplas rotas de transmissão do vírus Zika: transmissão vetorial (por meio da picada de um mosquito), transmissão por fluidos (por meio, por exemplo, do sêmen) e transmissão vertical (por meio da placenta para o feto no útero). Ao analisar as passagens de patógenos de um organismo para outro e as formas como essas passagens são entendidas, investigadas e (des)consideradas, abordamos, simultaneamente, aspectos biológicos e culturais. Argumentamos que uma antropologia, centrada na transmissão, permite elucidar as materialidades corporais, os significados simbólicos e as consequências políticas do movimento de patógenos de um organismo para outro, como relações entre humanos e não humanos. Sugerimos aqui que essa "antropologia da transmissão" também possibilita o desenvolvimento de políticas públicas mais abrangentes e inclusivas.

Palavras-chave: Zika. Antropologia da Ciência. Relações Humanos - Não Humanos. Estudos Feministas da Ciência.

\section{Abstract}

In Brazil, Zika is framed as a virus transmitted only by mosquitoes and the epidemic as a concern only for women. In order to examine this misconception, this article investigates the multiple transmission routes of the Zika virus: vectorial transmission (via mosquito bite), transmission through bodily fluids (via, for example, semen), and vertical transmission (via the placenta to the fetus in the womb). When analyzing the passages of pathogens from one organism to another and the ways in which these passages are understood, investigated and (dis)considered, we simultaneously address biological and cultural aspects. We argue that an anthropology centered on transmission can elucidate the bodily materialities, symbolic meanings, and political consequences of the movement of pathogens, understood as relationships between humans and non-humans. We suggest here that this "anthropology of transmission" can also lead to the development of more comprehensive and inclusive public policies.

Keywords: Zika. Anthropology of Science. Human - Nonhuman Relations. Feminist STS. 


\section{Introdução: uma Antropologia da Transmissão}

Togo pela manhã, Ana, uma mulher branca de quase 30 anos, espalha,

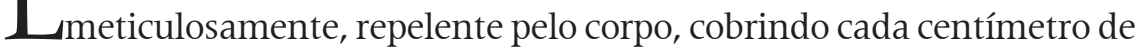
pele. Apesar do calor, ela decide usar sapatos fechados, calça e uma blusa com mangas compridas. Ana terá vários compromissos em diferentes bairros hoje, terá que passar o dia movendo-se pela cidade. Mesmo dirigindo seu próprio carro, com janelas fechadas e ar-condicionado ligado, ela quer garantir que não será picada por um mosquito. Ana está grávida de cinco meses e sabe que o vírus Zika está circulando em seu município. Essa narrativa ficcional condensa diversos relatos que ouvimos, ao longo dos anos de 2015 a 2018. Foram histórias de mulheres que se viram responsáveis, sozinhas, por proteger a si mesmas e a seus (futuros) filhos da picada de um mosquito potencialmente infectado, embora a transmissão por fluidos corporais fosse cientificamente reconhecida, principalmente por meio da relação sexual. No caso de Ana, seu companheiro, Marcos, não estava fazendo nada para evitar as picadas de mosquitos, e eles não estavam usando camisinha. Neste artigo, analisamos as condições e os efeitos da errônea apresentação, no Brasil, do Zika como um vírus transmitido somente por mosquitos e a epidemia como uma preocupação somente para mulheres - como gestantes ou pessoas capazes de gestar ${ }^{1}$.

Examinamos como políticas públicas de prevenção se concentraram, quase exclusivamente, no controle do vetor, o mosquito Aedes aegypti ${ }^{2}$, e como esse foco reforçou a ideia de o Zika ser um "problema de mulher", marcado por desigualdades de classe e de cor/raça. Para isso, propomos aqui uma "antropologia da transmissão": uma análise que examina os complexos enredamentos das múltiplas rotas de 
transmissão do vírus Zika - transmissão vetorial (por meio da picada de um mosquito), transmissão por fluidos (por meio, por exemplo, do sêmen) e transmissão vertical (por meio da placenta da mãe para o feto no útero). Procuramos demonstrar que uma antropologia atenta e centrada nas transmissões evidencia que essas são relações - entre humanos e entre humanos e não humanos - caracterizadas por questões históricas e estruturais.

Abordar a transmissão de patógenos não é algo novo na antropologia, ainda que, muitas vezes, esse tema tenha sido discutido de maneira indireta. Antropólogas 3 da saúde, assim como historiadoras e sociólogas, examinaram de que maneira rotas de transmissão e narrativas, feitas acerca dessas rotas, são influenciadas por desigualdades sociais, econômicas e raciais, além de fatores políticos e ecológicos investigando, por exemplo, surtos e epidemias de cólera (BRIGGS; MANTINI-BRIGGS, 2003) ou de tuberculose (BURKE, 2011). Em seu estudo sobre HIV/AIDS, o antropólogo médico Paul Farmer (1992) demonstra que a propagação do vírus e, consequentemente, a epidemia no Haiti - país estigmatizado por ser uma perigosa "fonte" do patógeno estavam vinculadas à longa história de exploração do país pelos Estados Unidos e, em particular, a catastróficas mudanças ocasionadas por um projeto de barragem. Pesquisadores e ativistas examinaram, ademais, as implicações da transmissão do vírus HIV e as graves repercussões da epidemia de AIDS nos anos de 1980 para a comunidade LGBT+, principalmente homens gays, grupo que foi fortemente afetado e estigmatizado pela epidemia (SHILTS, 1987; SONTAG, 1989; TREVISAN, 1986). Enquanto alguns estudos etnográficos se debruçaram sobre as subjetividades construídas em relação à transmissão do HIV (SANGARAMOORTHY, 2012; VALLE, 2002), outros analisaram a criminalização da transmissão do vírus no contexto jurídico brasileiro (NELVO, 2017). Uma análise antropológica comparativa feita por Adia Benton, Thurka Sangaramoorthy e Ippolytos Kalofonos (2017) mostrou que acusações de "atraso" e "problemas culturais" ainda estão presentes no discurso contemporâneo de campanhas sanitárias para justificar, ou melhor, culpabilizar determinados locais e comunidades pelas altas taxas de transmissão. A epidemia de Zika no Brasil foi, do 
mesmo modo, caracterizada por essa responsabilização da transmissão: no caso, mulheres que, supostamente, não se protegiam devidamente das picadas de mosquitos.

Além da extensa literatura antropológica examinando de que maneira as rotas de transmissão são influenciadas pelas estruturas sociais e, do mesmo modo, como essas rotas influenciam as experiências e entendimentos sobre doenças (GONÇALVES, 1998; LINDENBAUM, 2001), recentemente, estudos etnográficos vêm examinando as "proximidades materiais" da transmissão, levando em conta a "heterogeneidade espaçotemporal e a substância sociopolítica da propagação patogênica" (BROWN; KELLY, 2014, p. 282, tradução nossa). Considerando o vírus Ebola na África Ocidental, foi realizada uma série de intervenções antropológicas, com muitas pesquisadoras contribuindo nos esforços de entender e conter a epidemia (ABRAMOWITZ, 2017). Aspectos ligados justamente à transmissão foram centrais nessas análises. A antropóloga Denise Pimenta (2019), por exemplo, investigou os vínculos entre a disseminação do vírus e os afetos e as obrigações de parentesco, através de um "cuidado perigoso" - trabalho feito majoritariamente por mulheres. A infecciosidade do vírus, mesmo muitas horas depois da morte, trouxe à tona a necessidade de se discutir e propor soluções para lidar com o luto, o enterro e os mortos (LE MARCIS, 2015; MORAN, 2017; RICHARDS; MOKUWA, 2014). Nossa pesquisa leva em conta as proposições e recomendações desses estudos, ao sugerir que uma antropologia das transmissões pode servir de base no desenvolvimento e na implementação de melhores respostas sanitárias.

Tanto o HIV quanto o Ebola são, originalmente, vírus zoonóticos, provenientes de animais não humanos. Vários estudos antropológicos investigam as condições e consequências das relações multiespécies para a saúde, analisando a ecologia, a biopolítica e o cuidado como fundamentais para entender as doenças ocasionadas por patógenos zoonóticos (KELLY; KECK; LYNTERIS, 2019; MUEHLENBEIN, 2016; SODIKOFF, 2016) - ou, em certos casos, patógenos humanos transmitidos para outros animais (CABALION et al., 2018; LAINÉ, 2018). Além do mais, uma atenção às relações multiespécies faz 
parte do modelo de "One Health", ou "Uma Saúde" - uma abordagem transdisciplinar que reconhece "a interconexão entre pessoas, animais, plantas e seu ambiente compartilhado" como sendo central para a compreensão, a prevenção e o atendimento de questões ligadas à saúde (OMS, 2017, tradução nossa). Há muitas antropólogas envolvidas em projetos de One Health, apesar das críticas de que, frequentemente, a disciplina está relegada a um papel limitado e secundário e de que nem sempre é possível traduzir essa abordagem para as diferentes escalas e práticas envolvidas na produção de saúde (CRADDOCK; HINCHLIFFE, 2015; SMITH; TAYLOR; KINGSLEY, 2015). Iniciativas One Health tendem a favorecer análises preditivas sobre transmissão, ao passo que este artigo se inspira em estudos que ponderam sobre as dimensões afetivas, simbólicas, políticas e econômicas das relações entre humanos e não humanos na constituição da saúde (BROWN; NADING, 2019). Com o intuito de contribuir para esse debate, demonstramos que a passagem de patógenos de um organismo para outro e as formas como essas passagens são entendidas, investigadas e (des)consideradas nos permitem identificar a transmissão como um processo biológico e, ao mesmo tempo, político e social.

Enquanto a maioria dos estudos antropológicos examinando Zika no Brasil destacaram a incerteza como característica definidora da epidemia (DINIZ, 2016; HENDERSON; BARDOSH, 2020; KELLY et al., 2020; PRADO, 2018), neste artigo nós nos debruçamos sobre duas certezas que rapidamente se constituíram na narrativa de saúde pública. A primeira: a certeza de que o foco deveria ser a transmissão não humana (picadas de mosquito), enquadrado como parte de uma questão histórica. A segunda: a certeza de que, com a possibilidade e, depois, com a confirmação da transmissão vertical/placentária, a solução mais eficaz para mitigar os efeitos do Zika seria uma abordagem generificada das responsabilidades individuais de controle da infecção. Assim, por meio da análise das múltiplas rotas de transmissão, delineamos as condições que levaram Zika a ser apresentada como uma epidemia sobre mosquitos e mulheres e traçamos caminhos para se pensar políticas públicas mais abrangentes e inclusivas. 


\section{Rotas da Pesquisa}

O estudo desenvolvido neste artigo é fundamentado em diversos dados coletados nos últimos anos, desde o começo da epidemia. Uma das autoras desenvolveu, entre 2018-2019, 18 meses de pesquisa etnográfica com diferentes grupos implementando estratégias de controle vetorial. Temos como base, também, um conjunto de entrevistas com pesquisadores em diferentes cidades brasileiras, como Brasília, Rio de Janeiro, São Paulo, Recife, Salvador e Campina Grande, realizadas em parceria com a Rede Zika Ciências Sociais ${ }^{4}$, um esforço liderado pela Fundação Oswaldo Cruz (FIOCRUZ) para compreender melhor a epidemia de Zika no Brasil. Diferentemente dos "médicos de beira de leito", apresentados pela a antropóloga Débora Diniz (2016), em seu estudo sobre Zika no sertão brasileiro, a maioria dos nossos entrevistados atuavam (e ainda atuam) em centros de pesquisa integrados ao Sistema Único de Saúde (SUS). Assim sendo, estão posicionados para estabelecer conexões entre as unidades de assistência à saúde e unidades de pesquisa, entre atendimento e investigação científica. Tais entrevistas ocorreram ao longo de 2018, com atores-chaves selecionados por estarem envolvidos em pesquisas estratégicas sobre a epidemia. Sinalizamos que elas foram realizadas conforme os preceitos estipulados no Termo de Esclarecimento Livre e Consentido e, portanto, respeitamos a privacidade e o anonimato daqueles que, gentilmente, concordaram em conversar conosco.

Ademais, participamos de conferências, reuniões e oficinas relacionadas as mais variadas disciplinas abordando a epidemia de Zika, no Brasil e no exterior (Estados Unidos, França e Inglaterra), e de encontros organizados pelos Ministérios da Saúde e da Ciência, Tecnologia e Inovação brasileiros. Esses eventos foram frutíferos para a coleta de dados, pois, conforme nos lembra o antropólogo da ciência, Stefan Helmreich (2014, tradução nossa), estes são os "momentos em que uma comunidade torna explícita para si rivalidades históricas, quebra-cabeças presentes e possíveis futuros". Por fim, examinamos documentos governamentais tanto do Brasil quanto de outros países, como os do Centros de Controle e Prevenção de Doenças (CDC), dos Estados Unidos, e de instituições internacionais, como os da Organização 
Mundial de Saúde (OMS), reportagens e entrevistas com políticos, funcionários públicos e pesquisadores, veiculados na mídia, e artigos científicos sobre o vírus Zika e sua epidemia.

A partir desses dados, examinamos a epidemia em suas múltiplas rotas de transmissão. Nossa proposta se inspira em esforços de uma antropologia viral, por exemplo, a "patografia" desenvolvida pela antropóloga médica e pesquisadora dos estudos sociais da ciência Theresa MacPhail (2014) $)^{5}$. A patografia, que na medicina significa a descrição da progressão de uma enfermidade, é utilizada por MacPhail para estender as possibilidades da etnografia, tendo como foco uma doença (no caso dela, a gripe H1N1), e desenvolver uma metanarrativa sobre os vários fragmentos que constituem um surto, epidemia ou pandemia. No entanto, enquanto MacPhail centra sua análise na informação - sua transmissão, replicação e mutação - e nas redes virais, esse artigo focaliza nas transmissões em si. Propomos uma investigação antropológica que, a fim de melhor entender a caracterização de uma doença ou epidemia, examina os estudos científicos sobre as rotas de transmissão, as políticas públicas elaboradas para conter tais transmissões, as reflexões e os comentários acerca das diferentes rotas e os efeitos corporais e simbólicos da transmissão como uma relação entre humanos e não humanos.

\section{Zika na História}

Antes da epidemia no Brasil, o Zika era visto tão somente como mais um vírus na longa lista de patógenos transmitidos por mosquitos como o A. aegypti. Isolado pela primeira vez em abril de 1947, em uma floresta em Uganda chamada Zika (por isso o nome), o estudo sobre esse agente infeccioso - sua transmissão e seus efeitos - insere-se em uma longa história que perfaz caminhos de desigualdades engendrados por práticas coloniais e racistas (MAIO; SANTOS, 2010; ROBERTS, 2011). Pela descrição e análise do contexto e das circunstâncias em que o vírus foi identificado, argumentamos, nesta seção, que a própria conceptualização da transmissão do Zika constitui não somente um exercício epistemológico, mas, igualmente, um esforço situado dentro de 
um projeto social e político - entrelaçando, lembra-nos a pesquisadora da saúde coletiva Roberta Gondim (2018), corpos e territórios.

Em 1936, a Divisão Internacional de Saúde (IHD) da instituição estadunidense Fundação Rockefeller ${ }^{6}$, em parceria com o governo colonial de Uganda, inaugurou o Instituto de Pesquisa da Febre Amarela (YFRI) nas instalações do antigo Instituto de Pesquisa de Tripanossomíase, localizado no topo de uma colina com vista para o Lago Vitória, em Entebbe - a cerca de 11 quilômetros da floresta de Zika (CUMMISKEY, 2017). O YFRI foi estabelecido com o intuito de entender a transmissão de febre amarela na África Oriental e, com base nesse conhecimento, facilitar a implementação de projetos coloniais britânicos. Em especial, buscava-se impedir que a doença se espalhasse ao leste das cidades portuárias do Oceano Índico. Administradores coloniais temiam que o vírus atravessasse o mar e infectasse o subcontinente indiano, considerado "a joia da coroa do império britânico" (CUMMISKEY, 2020, p. 5, tradução nossa).

Em seu estudo sobre o YFRI, a historiadora da ciência e da saúde, Julia Cummiskey $(2017 ; 2020)$, mostrou que as pesquisas desenvolvidas nesse centro faziam parte de um projeto colonial no qual britânicos e estadunidenses tinham o poder de organizar, disciplinar e reconfigurar pessoas e suas moradas, mosquitos e macacos com o objetivo de transformá-los em locais experimentais, sem considerar as necessidades ou os desejos dos próprios habitantes. Estudos desenvolvidos pelo instituto não somente produziram conhecimento sobre a febre amarela (e outras enfermidades), mas também aperfeiçoaram a capacidade e as técnicas da administração colonial de governar e explorar a área (CUMMISKEY, 2020, p. 5).

Em um de seus experimentos, cientistas norte-americanos e europeus, junto a técnicos africanos ${ }^{7}$, colocavam macacos-rhesus - animais importados ou reproduzidos em cativeiro no YFRI - em plataformas de madeira no alto das árvores na floresta Zika (DICK; KITCHEN; HADDOW, 1952). Esses primatas eram usados para detectar patógenos potencialmente perigosos para a saúde humana, com seus corpos transformados no que os antropólogos Frédéric Keck e Andrew Lakoff (2013) descrevem como "dispositivos sentinelas", a 
instrumentalização de não humanos para identificar futuras ameaças e riscos a seres humanos. Esses macacos tinham suas temperaturas corporais medidas todos os dias, e, em 18 de abril de 1947, um deles identificado como Rhesus 766 - encontrava-se febril. No dia seguinte, sua temperatura havia aumentado, e o primata foi levado para o laboratório do instituto em Entebbe. Lá, coletaram seu sangue, e o soro deste foi inserido em camundongos. Nesse material coletado do cérebro desses roedores, um "agente transmissível filtrável," um vírus, foi isolado (DICK; KITCHEN; HADDOW, 1952, p. 510, tradução nossa). No ano seguinte, em janeiro de 1948, ele foi novamente isolado, desta vez em mosquitos Aedes africanus capturados na floresta de Zika. Após uma série de testes sorológicos, pesquisadores concluíram que "[...] a patogenicidade e as propriedades do vírus Zika tendem a diferenciá-lo de outros vírus, e acredita-se que o vírus Zika seja um vírus até então não descrito" (DICK; KITCHEN; HADDOW, 1952, p. 519, tradução nossa). Havia sido identificado, então, o vírus Zika - com o estabelecimento do modo de transmissão pelas picadas de mosquitos infectados.

Estudos de historiadores da ciência e da saúde nos mostram que a descoberta, no começo do século XX, da transmissão de certos patógenos por insetos, principalmente mosquitos, transformou drasticamente as políticas de contenção da transmissão: esses animais se tornaram o alvo das estratégias para controlar as doenças ocasionadas por tais patógenos (BENCHIMOL, 1999; HAYNES, 2001). É de se acrescentar que a descoberta da existência de insetos como vetores - organismos com capacidade de transmitir parasitas, bactérias ou vírus a outros organismos - resultou na consolidação do campo da medicina tropical, cristalizado no estabelecimento de novas instituições médicas europeias e norte-americanas nas "regiões tropicais" do mundo (CHAKRABARTI, 2014). Nas palavras da historiadora da ciência Marilia Coutinho (2003, p. 78, tradução nossa), a transmissão vetorial “[...] forneceu um meio para separar as doenças tropicais das doenças infecciosas cosmopolitas. As doenças tropicais foram definidas como aquelas transmitidas por um vetor".

Apesar de relatos e estudos históricos nos lembrarem que epidemias de doenças vetoriais ocorriam em partes da Europa e dos Estados 
Unidos até o século passado (OLIVARIUS, 2019) e de surtos ainda acontecerem nos dias de hoje (MORENS; FOLKERS; FAUCI, 2019), essas enfermidades foram, historicamente, construídas como "doenças tropicais," restritas a regiões específicas do mundo (PACKARD, 2007). A partir de uma perspectiva médica euroestadunidense, a presença de patógenos e seus vetores delineava o que eram os "trópicos", definindo como essa região deveria ser estudada e policiada (DELAPORTE, 1991; STEPAN, 2001). No Brasil, a descoberta de insetos-vetores foi vista pelas elites científicas e políticas como uma oportunidade para livrar o país das doenças que o assolavam, ao mesmo tempo que se produzia conhecimento científico, afirmando o prestígio nacional perante a comunidade internacional. Campanhas nacionais para eliminar o A. aegypti no início do século XX, na época vetor do vírus da febre amarela, tornaram-se uma política emblemática, visando "modernizar" e "civilizar" o país (LÖWY, 2006). Essas campanhas estavam vinculadas às políticas racistas e eugenistas, que incentivavam a imigração de europeus (brancos) para "embranquecer" o país - já que a febre amarela poderia matar e afugentar esses novos imigrantes/ colonizadores, considerados particularmente susceptíveis à doença (CHALHOUB, 1993; LOPES; REIS-CASTRO, 2019).

A febre amarela no Brasil é, todavia, só um entre vários exemplos de esforços para controlar a transmissão do vírus e eliminar o insetovetor, os quais resultaram em políticas que almejavam de facto controlar ou mesmo eliminar pobres, negros, colonizados ou subalternos dessas regiões (ANDERSON, 2006; MAVHUNGA, 2011) - grupos que muitas vezes eram vistos como "menos que humanos", como animais (FANON, 1963, p. 42; JACKSON, 2020). Nas seguintes seções, contribuímos para essa literatura acerca dos enredamentos, marcados por desigualdades históricas e estruturais, entre humanos, vetores e patógenos, ao examinar as transmissões como relações corporais, simbólicas e políticas.

\section{Zika e a Infraestrutura de Controle Vetorial no Brasil}

Após ser caracterizado nos anos de 1940, o Zika passou as décadas que se seguiram quase despercebido. No entanto, em 2007, foi relatado o primeiro surto em humanos, em Yap, ilha que faz parte dos Estados 
Federados da Micronésia (DUFFY et al., 2009). Em 2013-2014, houve novos surtos em outras ilhas do Pacífico; na Polinésia Francesa, o vírus infectou milhares de pessoas (MUSSO; NILLES; CAO-LORMEAU, 2014). Seria no Brasil, porém, que Zika tomaria proporções de emergência de saúde ${ }^{8}$. Examinamos, nesta seção, a chegada do vírus ao país e sua inclusão em uma infraestrutura sanitária historicamente voltada ao controle de vetores para lidar com arboviroses - as doenças ocasionadas por um vírus transmitido pela picada de mosquitos infectados ${ }^{9}$.

Em 2015, pesquisadores observaram um cluster no estado da Bahia envolvendo casos de manchas vermelhas, exantemas e febre baixa (CAMPOS; BANDEIRA; SARDI, 2015). Por meio da análise dos quadros clínicos e do diagnóstico laboratorial (RT-PCR), esses pesquisadores estabeleceram a relação entre tais sintomas e a presença de um novo vírus no país. A princípio, Zika foi considerado tão somente como mais um patógeno transmitido pelo $A$. aegypti, espécie de mosquito que, há mais de cem anos, vem sendo alvo de campanhas sanitárias no Brasil (LOPES; REIS-CASTRO, 2019). Quando Zika começou a circular, já estava implantada, no país, uma extensa infraestrutura - ou seja, "redes construídas que facilitam o fluxo de bens, pessoas ou ideias" (LARKIN, 2013, p. 328, tradução nossa) - para lidar com a transmissão dos vírus transmitidos por esse inseto.

Visando, naquele momento, principalmente à dengue e à chikungunya, essa infraestrutura girava, quase exclusivamente, em torno de estratégias para controlar a população do mosquito (SEGATA, 2017). Anúncios na mídia apresentavam o mosquito como inimigo (e ainda o fazem), enfatizando que, para lidar com as arboviroses, é preciso eliminar acúmulos de água parada, os criadouros do $A$. aegypti. Livros didáticos examinam essas doenças e, além de discutir aspectos da transmissão e dos sintomas, reforçam para as crianças, desde cedo, a importância de eliminar criadouros, de não deixar o mosquito procriar (ASSIS; PIMENTA; SCHALL, 2013). O Ministério da Saúde conta com agentes de combate à endemia, profissionais treinados especificamente para controlar as zoonoses - doenças causadas por patógenos zoonóticos -, sobretudo aquelas ocasionadas pelos vírus transmitidos pelo Aedes. Esses agentes visitam casas para 
inspecionar (potenciais) focos, utilizando larvicidas se necessário, e esclarecem os moradores a respeito dos perigos dos mosquitos, da transmissão, dos sintomas e das consequências dos arbovírus (ZARA et al., 2016). O controle do vírus recém-chegado ao país foi incluído nessa infraestrutura, que passou a enfrentar a "ameaça tripla" - Zika, dengue e chikungunya - das picadas de mosquitos.

Anuncia-se, desse modo, uma "luta" contra o mosquito, através da máxima "Não deixe água parada". Como indicam Cymene Howe et al. (2016, p. 548), toda infraestrutura está imbuída de significados sociais e reflete prioridades e atenções. A infraestrutura de saúde para a prevenção de transmissões incorpora uma racionalidade política, técnicas administrativas e materialidades que não somente contribuem para controlar o $A$. aegypti, mas também, ao enfatizarem a eliminação do vetor como a única solução para enfrentar as arboviroses, reforçam a associação entre o inseto e a doença. Ou seja, ela reifica a ideia de que dengue, chikungunya ou Zika não são apenas transmitidos pelo $A$. aegypti, mas também que as doenças ocasionadas por esses vírus são causadas pelo mosquito ${ }^{10}$. O A. aegypti, historicamente concebido como o inimigo, como o "vilão epidêmico", se torna o alvo dos esforços para lidar com as arboviroses (LOPES; REIS-CASTRO, 2019). Esforços esses que tendem a responsabilizar indivíduos no "combate" ao vetor, geralmente ignorando as condições sociais e econômicas que permitem que essas doenças proliferem e que seus sintomas sejam sentidos de maneira mais acentuada por certas pessoas e comunidades.

O sangue obtido da picada é necessário para que mosquitos possam assegurar sua reprodução, ao passo que para os humanos serem picados pode ser não apenas irritante, como também perigoso. O momento em que a probóscide do inseto entra em contato com a pele e em que sangue e saliva se misturam revela a permeabilidade e porosidade do corpo humano - uma interação multiespécie em que a troca de fluídos representa a sobrevivência para uns, mas uma potencial ameaça para outros (REIS-CASTRO, 2020). É pela picada, encontro corporal entre mosquitos e humanos, que arbovírus podem circular. No caso do Zika, para além da possível transmissão através de fluidos, os sintomas amenos causados nos corpos infectados possibilitaram que o vírus 
circulasse de maneira discreta. Entretanto, a circulação se tornou preocupantemente visível a partir de uma outra via de transmissão: a transmissão vertical. Relatos de mães apontam que elas não haviam entendido as implicações da infecção ou mesmo que desconheciam ter contraído o Zika (CARNEIRO; FLEISCHER, 2018). Isso resultou que, apesar da circulação do vírus, sua transmissão só tenha se tornado visível quando problemas de saúde foram identificados em fetos e em recém-nascidos.

\section{Ao Cruzar a "Barreira Placentária": Transmissão Vertical e Responsabilidade Materna}

Eu percebo que os homens se protegem. As mulheres normalmente ficam de perna de fora e, quando usam calça, usam sandália. [...] Nossa recomendação essencial, sobretudo mulheres nos três primeiros meses de gestação, é evitar de todas as maneiras, o contato com mosquito, de calça comprida, roupa, sapatos. Marcelo Castro, Ministro da Saúde na época. (ARAÚJO; PERON, 2015)

Sexo é para amador, gravidez é para profissional. A pessoa que vai engravidar precisa verdadeiramente tomar os devidos cuidados preparatórios antes e durante a gravidez. Marcelo Castro, Ministro da Saúde na época. (SOUZA, 2015)

Vamos torcer para que mulheres, antes de entrar no período fértil, peguem a Zika, para ficarem imunizadas pelo próprio mosquito. Marcelo Castro, Ministro da Saúde na época. (ARAÚJO, 2016)

Os enunciados que abrem esta seção, proferidos pelo Ministro da Saúde durante a epidemia, remetem, de maneira quase caricaturada, ao cerne do nosso argumento: na resposta ao Zika, houve uma ênfase, não apenas na transmissão vetorial, mas também na transmissão vertical como uma responsabilidade de mulheres/mães. Abordamos aqui esta transmissão e a maneira pela qual, após as imagens de crianças com cabeças pequenas desencadear várias indagações científicas relacionadas à capacidade do vírus de cruzar a "barreira placentária", a obrigação de se proteger do Zika recaiu sobre gestantes e pessoas capazes de gestar. 
No início de 2016, por meio da amniocentese - procedimento que consiste na aspiração transabdominal do fluido que preenche a bolsa amniótica e que envolve o feto -, cientistas detectaram genoma do Zika em duas gestantes. A presença do vírus nesse líquido amniótico indicava sua capacidade de atravessar a "barreira placentária", confirmando essa nova rota, também chamada de transmissão placentária (CALVET et al., 2016). Sua simples presença, todavia, não explica os efeitos do patógeno. Atualmente, sabe-se que o neurotropismo do Zika ${ }^{11}$ - uma afinidade das células do sistema nervoso com a estrutura do vírus -, resulta em que ele se conecte em partes do cérebro impedindo e, até mesmo, destruindo seu desenvolvimento (ALBUQUERQUE et al., 2018). Como relatou uma das nossas interlocutoras, médica que atendeu a várias gestantes infectadas, partes como o cerebelo (mas não apenas) apareciam, em imagens de ultrassom intrauterino, particularmente danificadas. É essa relação de afinidade entre vírus e células que causou o que é conhecido, hoje, como Síndrome Congênita do Zika Vírus (SCZV) - uma série de problemas de saúde em fetos e recém-nascidos, incluindo a microcefalia, o sintoma mais visível -, introduzindo novos e desconhecidos desafios para cientistas, funcionários da saúde pública e gestantes.

Foi o crescimento súbito no número de casos de microcefalia, e sua possível correlação com o Zika, que propulsionou a declaração de Emergência de Saúde Pública de Importância Nacional (ESPIN), em novembro de 2015. Três meses depois, em fevereiro de 2016, a OMS anunciou uma Emergência de Saúde Pública de Importância Internacional (PHEIC), baseada, principalmente, na suspeita de correlação entre a infecção pelo Zika e o aumento repentino de casos de microcefalia no Brasil (KELLY et al., 2020; NUNES; PIMENTA, 2016) - um alerta global que durou nove meses. Quando a OMS declarou à PHEIC, a hipótese de que Zika poderia atravessar a "barreira placentária" necessitava de evidências a serem obtidas através de estudos de caso e de coorte (BRITO, 2015). A médica e epidemiologista Celina Turchi, responsável por um dos principais estudos de caso analisando a relação entre microcefalia e Zika, relatou ao jornal britânico The Guardian a complexa relação e implicações do vírus e suas várias rotas de transmissão: 
Se eu fosse uma cineasta oferecendo um cenário como esse, as pessoas diriam que eu era louca - uma doença congênita transmitida por um vetor, que está em toda parte, e que também pode ser transmitida sexualmente? Desde o primeiro momento, tive a sensação de estar em um filme de terror e não ter cura para ele. (BOSELEY, 2016, tradução nossa)

Para a pesquisadora, a epidemia instituía um quadro assustador ${ }^{12}$ devido às múltiplas rotas, em que vetores e parceiros infectados transmitiam o vírus de maneira indetectável e inadvertida, com consequências significativas para a saúde de fetos e recém-nascidos. Tudo isso, sem a possibilidade de imunização por uma vacina ou de um tratamento eficaz. Muitas das pesquisadoras com quem conversamos, principalmente aquelas ligadas ao atendimento, relataram como o alto número de bebês com microcefalia e outras doenças congênitas as impactou profundamente e as motivou em seus estudos sobre Zika.

Esses efeitos, que impulsionaram tanto as pesquisas científicas quanto as respostas de saúde pública, foram também a forma como o Zika se fez mais presente. Os sintomas leves (quase desconsiderados) da doença resultaram na circulação quase invisível do vírus, uma circulação que deixava poucos rastros até o aparecimento de sintomas congênitos em fetos e bebês. Relatos indicam que, em muitos casos, as mulheres souberam, durante seus exames de ultrassom - com a identificação das implicações na formação fetal condizente com a SCZV (ALBUQUERQUE et al., 2019). Ou mesmo, descobriram, somente após o parto, que haviam sido infectadas (CARNEIRO; FLEISCHER, 2018). Além disso, muitas crianças que não demonstraram nenhum sinal de microcefalia quando nasceram, ao crescerem, passaram a apresentar dificuldades no desenvolvimento cognitivo, casos de convulsões e outros problemas de saúde (PETRIBU et al., 2018). Em outras palavras, Zika possui múltiplas rotas de transmissão; porém, enquanto as transmissões vetorial e sexual acontecem de maneira (quase) imperceptíveis, a transmissão vertical causa consequências explícitas e duradouras. Consequências essas que definiram os rumos políticos da epidemia (LÖWY, 2019). 
Como evidenciam as frases do Ministro que abrem esta seção, a transmissão vertical foi generificada, ao recomendar às mulheres que evitassem, por conta própria ${ }^{13}$, as picadas de mosquitos - ao mesmo tempo em que o silêncio sobre a possibilidade da transmissão sexual as manteve em risco de infecção (BORGES et al., 2018). Diversas antropólogas e historiadoras analisaram essa responsabilização de mulheres acerca da transmissão vertical, com pesquisas sobre esta via de infecção relacionadas à rubéola, à sífilis e ao HIV/AIDS (CARRARA, 1996; COITINHO FILHO, 2017; REAGAN, 2012). Assim como na epidemia de Zika, esses estudos afirmam que a transmissão vertical foi caracterizada como um "problema" de mulheres.

Tal caracterização da transmissão está associada a ideias que, similarmente, definem reprodução e gestação como sendo "problemas" de mulheres. Diversos estudos antropológicos analisam a construção de figuras maternas e as teias de responsabilidades que as envolvem (FERNANDES, 2019; FONSECA, 2007). A epidemia de Zika atualiza antigas percepções sobre mulheres e maternidades "responsáveis" reveladas, por exemplo, na responsabilização feminina em evitar a gestação (PORTO; MOURA, 2017), assim como nos atos cotidianos de cuidado com os bebês (ALVES; FLEISCHER, 2018; SCOTT et al., 2018; WILLIAMSON, 2018). As antropólogas Ana Cláudia Rodrigues da Silva, Silvana Sobreira de Matos e Marion Teodósio de Quadros (2017) apontam como essa incumbência faz parte da configuração da cidadania e da relação que se estabeleceu entre as mães e o Estado. Em certos momentos, destacava-se a importância dos esforços governamentais em garantir respostas satisfatórias, principalmente para as mais vulneráveis; em outros, esses esforços estavam voltados, justamente, em delegar as responsabilidades às mães.

Foi a ênfase na transmissão vertical, combinada com a ênfase na transmissão vetorial, que resultou na definição do vírus como transmitido apenas por mosquitos e como uma preocupação apenas para mulheres, reforçando suposições generificadas de responsabilidade materna. De acordo com as palavras do Ministro, percebe-se que as mulheres, entendidas como pessoas que gestam, no presente e no futuro, deveriam considerar a ideia (não comprovada cientificamente) 
de uma "imunização preventiva"14. Mais que isso, as frases do Ministro também evidenciam que, a despeito de esforços para controlar os mosquitos, opera-se com a certeza de que eles permanecerão na paisagem do país como vetores de vírus. Nessa percepção, o corpo da mulher é considerado como algo a ser administrado em relação a (possíveis) patógenos e efeitos negativos para o (possível) feto, pois é um corpo caracterizado como espaço de reprodução, definido por sua capacidade de gestar e (re)produzir. Estudos antropológicos sobre noções epigenéticas examinaram essa concepção do corpo feminino, identificando o entrelaçamento entre expressões de genes, ambientes, substâncias e seres não humanos. Alimentos consumidos, doenças preexistentes (ainda que latentes), toxinas, bactérias e vírus (como o Zika): o que se partilha, antes, durante e após a gestação, torna-se importante pois produz efeitos na linha de descendência, muitas vezes acompanhados por sentimentos de responsabilidade e culpabilização materna (LAMOREAUX, 2016; YATES-DOERR, 2011).

$\mathrm{O}$ "filme de terror", narrado por Turchi, refere-se a esse compartilhamento do Zika, que se efetua à revelia, geralmente sem conhecimento prévio do indivíduo. Um patógeno que se move entre saliva de mosquitos e sangue humano, entre corpos humanos, através de fluidos, e entre gestantes e fetos, pela placenta. A placenta, órgão que se desenvolve no útero durante a gravidez, fornece oxigênio e nutrientes e remove resíduos do sangue do feto, atuando diretamente na produção de um ambiente "limpo". A literatura médica descreve a placenta como sendo, ao mesmo tempo, "um filtro passivo e um participante ativo nessas trocas" (LATENDRESSE; FOUNDS, 2015, p. 361, tradução nossa). Ao atingir o líquido amniótico, Zika foi definido como "atravessando" a "barreira placentária", subvertendo aquilo que deveria ser uma proteção. Entretanto, os sociólogos Aryn Martin e Kelly Holloway (2014) constataram que o conceito de "barreira placentária" passou a ser utilizado apenas depois que a comunidade médica havia identificado certas substâncias capazes de "atravessar" a placenta - no caso, duas drogas (talidomida e DES), que, ao serem consumidas por gestantes, causaram efeitos congênitos em fetos e recém-nascidos. Zika, mais uma vez, demonstrou como a placenta é 
um espaço de partilhas, de trocas entre gestante e feto - um órgão que oferece, ao mesmo tempo, proteção, nutrientes e riscos.

Essas gestações atravessadas de partilhas, potencialmente contaminadas, revelam a placenta como um espaço que atualiza noções de pureza e perigo. De acordo com antropóloga Mary Douglas (1991), a relação entre a produção de um corpo sadio, ordenado, limpo e puro constitui um trabalho constante de arrumação e limpeza para (se) livrar de impurezas, dando sentidos às coisas e seus ambientes. A transmissão placentária, no cenário de epidemia de Zika, situa mulheres como responsáveis pela "pureza" de suas escolhas e de seus modos de vida e, concomitantemente, como ameaçadoras pois possivelmente carregadas de "perigos". O "filme de terror", para retomar uma vez mais à frase de Turchi, torna-se ainda mais complexo tendo em vista o silêncio acerca da transmissão sexual e das condições desiguais que mulheres têm de se proteger de picadas de mosquitos.

Igualmente desiguais foram as circunstâncias para exercer a autonomia reprodutiva no contexto do Zika (LÖWY, 2019; MELLO; RONDON, 2020). Mulheres de classe média/alta, majoritariamente brancas, podem realizar um aborto ilegal, porém relativamente seguro; mulheres pobres, majoritariamente negras e pardas, não podem arcar financeiramente com o procedimento e acabam arriscando a saúde e a possibilidade de serem encarceradas. As desigualdades sociais brasileiras exacerbaram as diferenças na possibilidade de se proteger e nos efeitos da transmissão do vírus Zika. Porém, devido ao silêncio sobre a transmissão sexual, mesmo aquelas que conseguiam evitar as picadas de mosquitos se mantiveram em risco de infecção.

\section{6 "Em um Lugar como o Brasil": mosquitos, sexo e as transmissões que (não) importam}

Em novembro de 2017, dois anos após a epidemia de Zika atingir o país, o Ministério da Saúde organizou um evento em São Paulo para discutir sobre o estado da pesquisa e identificar as inovações tecnocientíficas ligadas ao Zika Vírus. Esse evento reuniu formuladores de políticas públicas e renomados cientistas brasileiros e estrangeiros que investigavam o vírus, sua transmissão e seus efeitos. Um desses 
especialistas foi a virologista Van-Mai Cao-Lormeau do Instituto Louis Malardé, eminente pesquisadora do patógeno na Polinésia Francesa, onde houve um surto de Zika entre 2012 e 2013. Durante a sessão de perguntas com a Cao-Lormeau, o médico Pedro Vasconcelos, ex-diretor do Instituto Carlos Chagas, indagou sobre a importância da transmissão sexual e sua difícil abordagem no contexto brasileiro, "em que mosquitos proliferam mais rápido do que pensamento". Ao responder, a virologista argumentou que, assim como na Polinésia Francesa, seria impraticável delinear e medir, no Brasil, a porcentagem de casos provenientes de transmissões vetoriais e não vetoriais devido ao alto número do vetor $A$. aegypti. Segundo ela, apesar de uma melhor compreensão da transmissão sexual ser de extrema importância para a ciência, seria impossível, "em um lugar como o Brasil", identificar a relevância das diferentes rotas de transmissão que, ao espalharem o vírus, causam a epidemia. Após essas observações, Cao-Lormeau concluiu que as políticas públicas de prevenção nesses locais com "muitos mosquitos" deveriam se concentrar na transmissão vetorial.

De fato, o comentário da pesquisadora da Polinésia Francesa ecoou as políticas públicas de controle do vírus implementadas durante a epidemia no Brasil. Apesar da comprovação científica da transmissão por fluidos corporais, principalmente através do sexo (KIM et al., 2018), estratégias para limitar a propagação do vírus estavam centradas na figura do mosquito. Tal constatação ficou evidente em uma das entrevistas realizadas com um funcionário do Ministério da Saúde, que atuou, entre 2015-2016, na Sala Nacional de Coordenação e Controle, dispositivo intersetorial cujos dois principais objetivos eram, de acordo com nosso interlocutor, o controle vetorial e a assistência em saúde (materna e infantil). Quando questionado sobre a transmissão sexual do Zika, ele destacou que, embora houvesse evidências científicas em relação a essa rota, o foco do Ministério era e continuaria sendo o controle vetorial, uma vez que "no grosso do quantitativo dos casos notificados, [a transmissão sexual] deve ser uma pequena parte". Desse modo, nossos interlocutores - pesquisadores internacionais, nacionais, assim como funcionários públicos - parecem concordar que, “em um lugar como o Brasil", com alta prevalência, dispersão e densidade do vetor $A$. aegypti, Zika deve ser entendida e tratada como uma arbovirose. 
No Brasil, Zika foi caracterizada como uma doença vetorial; em outros, a transmissão por fluidos foi discutida e abordada. Casos de Zika em pessoas que não haviam visitado locais com mosquitos infectados, porém mantiveram relações sexuais com viajantes retornando de áreas afetadas pelo vírus, apontaram a necessidade de se investigar a transmissão por fluidos (KIM et al., 2018, p. e25). Um estudo de 2011 já indicava evidências clínicas e sorológicas da transmissão não vetorial do Zika: em 2008, dois cientistas estadunidenses retornaram de suas pesquisas no Senegal infectados pelo Zika e, um deles, já de volta aos Estados Unidos, transmitiu o vírus para a esposa (FOY et al., 2011). Em fevereiro de 2016, o CDC divulgou uma atualização do Relatório Semanal de Morbidade e Mortalidade, alertando a respeito da transmissão sexual e da transmissão por transfusão de sangue (HILLS et al., 2016) - embora o período de incubação e de viremia (a presença do vírus no corpo) fossem e ainda são desconhecidos.

Ao desconsiderar o movimento de patógenos através de fluidos, particularmente pela via sexual, a resposta brasileira à epidemia manteve mulheres em risco de infecção. Estudos indicam que até 73\% dos homens (cis), infectados pelo Zika, apresentaram o vírus em seu sêmen (STASSEN et al., 2018). É de se notar que pesquisas sugerem que Zika pode se replicar especificamente no trato genital masculino, persistindo no sêmen meses após a infeção, e que a longevidade e infecciosidade do vírus é maior no sêmen do que em fluidos vaginais - ou seja, as chances são maiores de um homem transmitir o Zika sexualmente (NICASTRI et al., 2016). Isso posto, mulheres foram acusadas e culpadas de terem uma taxa de infeção mais alta, ao passo que estudos mostram que essa diferença pode ser explicada pela continua transmissão sexual do vírus por seus parceiros (ALLARD et al., 2017; COELHO et al., 2016).

Essa opção pelo (relativo) silêncio acerca da transmissão sexual reitera noções generificadas sobre a (re)produção como cis-heterossexual e localizada apenas dentro do corpo das mulheres (ALMELING, 2015). Ao ignorar o corpo masculino no processo sexual e reprodutivo, apaga-se seu papel como transmissor ( sexual) do vírus. Além de desconsiderar a pluralidade de relacionamentos e identidades de gênero, a discussão sobre a epidemia, mesmo pautada na cis-heterossexualidade, sequer 
abordou questões como a necessidade de homens se protegerem contra a picada de mosquitos ou a utilização de preservativos para proteger parceiras. O corpo, a sexualidade e a capacidade reprodutiva dos homens estiveram totalmente alheios às narrativas e respostas epidêmicas ao Zika.

Entre o começo da epidemia até 2018, o Ministério da Saúde, no entanto, se pronunciou sobre a transmissão por fluidos com três notas técnicas. A primeira, emitida em 2015, por intermédio da Coordenação Nacional de Sangue e Hemoderivados, estabeleceu mudanças nos protocolos de transfusões de sangue, alertando profissionais de saúde para serem cuidadosos durante a triagem de doadores. O documento recomenda a testagem prévia, a fim de identificar aqueles que possam estar infectados pelo Zika (BRASIL, 2015). Uma segunda nota técnica preconiza que, caso esses testes sejam positivos, devem ser testados os parceiros sexuais da pessoa infectada (BRASIL, 2016a). Por serem direcionados a pacientes necessitando de transfusão de sangue, que acessam serviços de saúde tanto pelo SUS quanto pela rede privada, esses documentos se dirigiam à população como um todo.

Porém, a terceira nota, foca somente em um segmento específico da população. Em 2016, o Ministério da Saúde emitiu uma nota técnica proibindo a doação e importação de sêmen no caso de exames positivos ou inconclusivos para o Zika (BRASIL, 2016b). Ela se dirigia unicamente àqueles com acesso às tecnologias de reprodução assistida. Atualmente, em todo o país, existem só cinco unidades públicas de saúde que dispõem da alta complexidade em reprodução humana assistida (RHA). Em entrevistas com diretores de duas dessas unidades, ambos afirmaram que os referidos centros de RHA não permitem doação e/ou importação de sêmen ou oócitos. Nessas unidades de saúde pública, cada casal (heterossexual) pode utilizar apenas seus próprios fluidos reprodutivos (ETRINGER et al., 2020). Com isso, a doação e/ou importação de sêmen ou oócitos está facultada a segmentos sociais que podem ter acesso a esse tipo de procedimento. Portanto, a regulamentação, para evitar a transmissão via esses fluidos, destina-se ao setor privado de saúde, um mercado em expansão entre aqueles com poder aquisitivo (TIZIANO, 2011). 
Assim sendo, além de "em um lugar como o Brasil" as estratégias de prevenção ao Zika tenham sido (e ainda sejam) direcionadas para o controle vetorial, as proposições de um quadro normativo, voltado para o controle da transmissão por fluidos, foi majoritariamente direcionado para grupos específicos, em especial as classes altas. Ou seja, "em um lugar como o Brasil", além da alta prevalência de mosquitos e da consequente convicção de que se deve focar na transmissão vetorial, os poucos esforços para abordar as outras vias foram marcados pelas desigualdades sociais que também caracterizam o país.

\section{Desigualdades Sociais e Rotas de Transmissão}

Um estudo, publicado durante a epidemia (TRIUNFOL, 2016), afirmou que a maioria das gestantes, cujos fetos foram infectados pelo Zika, possuía baixa renda econômica. Esse mesmo trabalho destaca que, naquele momento, a principal recomendação do Ministério da Saúde era o uso de repelentes. No entanto, em um contexto de profundas desigualdades econômicas, sociais e raciais, indivíduos não possuem os mesmos recursos para se prevenirem da picada de mosquitos. Nesta seção, examinamos como as múltiplas rotas de transmissão e suas narrativas oficiais (ou silenciadas) estão intimamente ligadas às condições históricas e estruturais - Zika, no Brasil, entrelaça gênero, classe e raça ${ }^{15}$.

Em 2016, o Ministério da Saúde publicou um boletim epidemiológico temático intitulado "Zika vírus: perfil epidemiológico em mulheres", destacando que a maior parte das mulheres possivelmente infectadas pelo Zika se autodeclarava parda $(58,6 \%)$; em sequência, vinham as categorias branca $(33,3 \%)$ e preta $(6,4 \%)$. Autores como o sociólogo Carlos Hasenbalg (1979) apontam que pardos e pretos possuem indicadores socioeconômicos próximos. Em uma releitura sobre as dinâmicas do censo, o também sociólogo Luiz Augusto Campos (2013) demonstra como o Instituto Brasileiro de Geografia e Estatística (IBGE), desde 2011, traz uma opção de 'classificação' racial aberta - pretos e pardos - e outra que constitui a somatória de ambos - negros. Essa demarcação, tanto de separar como de agregar, torna-se relevante uma vez que a porção preta dos pardos os marca social e politicamente, ao 
mesmo tempo que, em um espectro imposto pelo racismo estrutural (ALMEIDA, 2019), os diferencia dos pretos. Essa é uma das faces da complexidade racial como construção societária no Brasil.

Estudos como o do Instituto de Pesquisa Econômica Aplicada (IPEA) (OSÓRIO, 2003) indicam que as condições de vida da população preta e parda produzem efeitos (perversos) nas determinações sociais do processo de construção da saúde e doença ${ }^{16}$. Como argumenta a médica Jurema Werneck (2016, p. 541-542),

[...] a dimensão mais negligenciada do racismo, desloca-se da dimensão individual e instaura a dimensão estrutural, correspondendo a formas organizativas, políticas, práticas e normas que resultam em tratamentos e resultados desiguais [...] [e] garante a exclusão seletiva dos grupos racialmente subordinados, atuando como alavanca importante da exclusão diferenciada de diferentes sujeitos nesses grupos.

Nesse sentido, as determinações sociais devem ser entendidas a partir da interseccionalidade (CRENSHAW, 2002), na qual aspectos como classe, gênero e raça agem como operadores que se interrelacionam na produção de discriminações. Tais discriminações - ou estratégias de invisibilização, como sugere Werneck (2008) - perpassam as vivências de pretos, pardos e incluem também as populações indígenas e ribeirinhas. Conforme aponta Jamille (Anahata) Nunes (2019), a categoria "pardo" e sua relação com o violento processo de colonização produzem complexas camadas de apagamento sobre o papel dos povos indígenas (presente e passado) na formação do país - ver também Oliveira (1997). Retomando o boletim epidemiológico, cabe destacar que $0,5 \%$ das mulheres possivelmente acometidas pelo Zika se identificam como indígenas. Vale dizer, tendo em vista esse boletim, que em torno de $66 \%$ das mulheres possivelmente infectadas pelo vírus Zika são pretas, pardas ou indígenas. Conclui-se, pois, que as rotas de transmissão do Zika precisam ser analisadas considerando o processo de produção de desigualdades sociais e seus impactos nas condições de saúde da população.

A cientista política Layla Pedreira Carvalho (2017) examina esses impactos desproporcionais nas populações negras (também pardas e 
indígenas) como um exemplo de racismo ambiental. Carvalho ressalta que as áreas marginalizadas das cidades, nas quais vivem populações majoritariamente negras e pobres, geralmente possuem os piores serviços públicos. A autora descreve, por exemplo, visitas a domicílios em Pernambuco, onde, devido à inconstância no abastecimento de água, havia vários reservatórios de água. A necessidade de manter esses reservatórios, locais propícios para se tornarem criadouros de mosquitos, claramente indica como a desigualdade social resulta em uma exposição desproporcional às picadas do mosquito.

Alguns estudos sugerem, entretanto, que a relação entre condições socioeconômicas e prevalência do A. aegypti pode ser mais complexa, tendo em mente que o mosquito prefere colocar seus ovos em água limpa (CASTRO; KHAWJA; JOHNSTON, 2010; MULLIGAN et al., $2015)^{17}$. Poças em piscinas vazias ou privadas pouco usadas podem se tornar criadouros nos bairros ricos da cidade. Pode ser igualmente difícil delinear e quantificar se a prevalência de doenças como a Zika é maior em certas partes do mundo e, no Brasil, em certas regiões do país, devido a condições climáticas ou aos efeitos do colonialismo e da exploração a que esses lugares foram submetidos, e consequentemente, das desigualdades sociais, dos desequilíbrios ambientais e da ausência de políticas e serviços públicos de qualidade. O que se pode afirmar, no entanto, é que, quando se trata de arboviroses, o acesso diferenciado à saúde, entendida de maneira ampla, exacerba as discrepâncias sociais. Nesse caso, a falta de saneamento, assim como as disparidades na qualidade dos serviços públicos - por exemplo, atendimento médico ou educação - podem até levar a uma maior proliferação de mosquitos, mas, principalmente, acabam tendo um efeito prejudicial em como se dá a reposta ao vírus. Afinal, corpos e ecologias saudáveis (ou não) se influenciam e se constituem ao longo do tempo (MORAN-THOMAS, 2019). Em outras palavras, se a oportunidade de alguém ser picado pode chegar a diferentes grupos, as desigualdades sociais, raciais e regionais determinam como a doença se manifesta e se desenvolve em cada indivíduo. ${ }^{18}$

Em momentos como o da epidemia de Zika, em que a principal recomendação governamental é o uso de repelente, preservar-se do vírus 
se torna ainda mais limitado àqueles que podem arcar financeiramente com o custo do produto. Portanto, as possibilidades de evitar as rotas de transmissão do Zika e também seus efeitos operam tendo em vista marcadores sociais que (re)produzem o distanciamento dos espaços de privilégios de uma certa branquitude (BRIDGES, 2009; SCHUCMAN, 2012). Como salientamos no relato etnográfico que abre este artigo - uma mulher branca, com acesso a repelente, que se protege das picadas do mosquito usando sapato fechado, calça e blusa de mangas compridas, no frescor do ar-condicionado de seu carro, porém, ainda assim pode ser infectada sexualmente pelo seu companheiro - as vias de transmissão perfazem e atualizam os caminhos das desigualdades econômicas e étnicas/raciais e também de gênero.

\section{Considerações Finais}

Floresta, macaco, império, mosquito, campanha, laboratório, placenta, sangue, sêmen, repelente, cuidado, saneamento: as “histórias de Zika" são múltiplas (REIS-CASTRO, 2019). Para examinar a epidemia de Zika no Brasil, optamos, neste artigo, por acompanhar as rotas de transmissão do vírus, estudando-as não só como processos biológicos, mas também políticos e sociais. Isto é, baseando-nos na proposta de desenvolver o que as pesquisadoras dos estudos sociais da ciência, Sophia Roosth e Astrid Schrader (2012), definem como "teoria feminista a partir da ciência", consideramos, conjuntamente, questões da antropologia e da biologia, para assim promover uma análise que examine tanto a materialidade corporal quanto os significados simbólicos e as consequências políticas das transmissões.

Ao longo deste artigo, afirmamos que a forma como a epidemia foi narrada pelas políticas públicas ignorou certas vias de transmissão - sobretudo a sexual -, desconsiderou condições estruturais que agravam as transmissões - como acesso desigual a saneamento e a atendimento médico -, e não levou em consideração as dificuldades sociais, econômicas e ambientais de se proteger, individualmente, da picada de mosquitos. Nossa análise é fundamentada na constatação de que a maneira pela qual uma epidemia é apresentada influencia e define o desenvolvimento das políticas públicas e pesquisas em 
saúde (HAMMONDS, 1997). Salientamos que a impossibilidade de se rastrear e quantificar a relevância da transmissão sexual resultou em que essa via tenha sido mantida alheia às respostas e narrativas epidêmicas. Ademais, identificamos que o foco na transmissão vetorial e na transmissão vertical levou à caracterização errônea de Zika como uma epidemia de mosquitos e mulheres.

Investigamos de que modo as respostas públicas foram pautadas e implementadas "em um lugar como o Brasil", marcado não somente por uma alta prevalência de mosquitos, mas também por gritantes desigualdades de gênero, de raça/cor e classe. Em vista disso, as maneiras pelas quais as diferentes rotas foram (des)consideradas exacerbaram essas desigualdades, tornando ainda mais perverso o complexo processo dos determinantes sociais de saúde. Estudos sobre arboviroses já demonstram que, ao focar no espaço doméstico, campanhas para eliminação do mosquito miram e sobrecarregam mulheres (CARVALHO, 2017; NADING, 2014; WENHAM et al., 2020), ao passo que nós discutimos como esse ônus é intensificado no que diz respeito ao Zika Vírus, pois elas foram vistas como responsáveis inclusive pelo controle da infecção. Há de se acrescentar que mulheres, marcadas pelas discriminações econômicas e de raça/cor, emergem apenas (e temporariamente) quando gestam bebês afetados pela SCZV e, ainda assim, sobre elas recaem a suspeita do não cuidado em evitar picadas de mosquitos, sobre elas é que são depositadas as expectativas políticas do cuidado com a criança (PRADO, 2018).

Uma "antropologia da transmissão", argumentamos aqui, permite analisar o que é transmitido, que conexões são estabelecidas na partilha de patógenos e de que maneira essas relações entre humanos e não humanos são entendidas em seus aspectos históricos e estruturais. Esse enfoque possibilita, igualmente, pensar em novas formas de definir e abordar doenças e epidemias e, em particular, em quem deveria se preocupar com elas. No caso do Zika, uma análise que leve a sério as rotas de transmissão demonstra a importância de se implementar políticas públicas de saúde que discutam a transmissão sexual, promovendo o uso de preservativos e enfatizando que não apenas mulheres, mas também seus parceiros devem prevenir-se para não 
serem infectados. Uma antropologia da transmissão revela, ademais, que, se fosse garantida a testagem extensiva para Zika (e também para dengue e chikungunya), aqueles que estivessem infectados poderiam cuidar para não serem picados por um A. aegypti, a fim de compartilhar a responsabilidade na disseminação dos vírus - afinal, o mosquito se torna um vetor somente após picar uma pessoa infectada. Ao desmontar suposições generificadas de responsabilização e culpabilização sobre a transmissão vertical, percebe-se a necessidade de garantir que pessoas com deficiência e suas famílias recebam apoio financeiro e cuidados médicos e de assegurar que as estruturas sociais sejam adequadas às suas necessidades. Vale ressaltar que se compreende, também, a urgência de consolidar o direito de interromper a gravidez (em qualquer circunstância). Se Zika, no Brasil, entrelaça gênero, classe e raça, uma antropologia da transmissão - sugerimos aqui - propicia uma rota para compreender e responder a esses enredamentos.

\section{Agradecimentos}

Um sincero agradecimento a Eliza Williamson, Ilana Löwy, Silvana Matos e Tullio Maia, cujas sugestões, recomendações e comentários foram fundamentais para melhorar nosso texto. Dois pareceristas anônimos, que se dispuseram a ler e comentar este trabalho, nos ajudaram a desenvolver e a refinar nosso argumento. Com sua revisão, Marlene Machado Zica Vianna nos guiou pelas rotas da escrita. Agradecemos à Rede Zika de Ciências Sociais pelo fantástico suporte, sem o qual este artigo não seria possível. O nosso muito obrigado para Soraya Fleischer e Jean Segata por, junto a Luísa Reis-Castro, organizarem este Dossiê, e para Viviane Vedana pela dedicação como editora da revista. As autoras gostariam de reconhecer o apoio do programa de pesquisa e inovação 2020 da União Europeia ZIKAlliance Grant Agreement n. 734548 e da Vice-Presidência de Pesquisa e Coleções Biológicas (VPPCB) da Fundação Oswaldo Cruz, em parceria com o Newton Fund/British Council. A pesquisa de doutorado da Luísa ReisCastro sobre estratégias de controle vetorial e seu trabalho de campo prolongado em diferentes cidades do Brasil foram possíveis graças a uma International Dissertation Research Fellowship da Social Science 
Research Council, a uma Doctoral Dissertation Research Improvement Grant (BCS-1823376) da National Science Foundation-Cultural Anthropology Program e a uma Dissertation Fieldwork Grant (Gr. 9677) da Wenner-Gren Foundation.

\section{Notas}

1 Reconhecemos que nem todas as mulheres são pessoas capazes de gestar e nem todas as pessoas que podem gestar são mulheres. No entanto, as narrativas e políticas públicas foram desenvolvidas supondo mulheres cis, capazes de gestar.

2 Umas das incertezas da epidemia de Zika foi a possibilidade de o vírus também ser transmitido por outro mosquito, o Culex (GUEDES et al., 2017) - ver Löwy (2019) para uma análise dessa controvérsia. Outro (provável) vetor do Zika é o Aedes albopictus, mosquito que habita as áreas periurbanas. Entretanto, as políticas públicas continuaram a mirar no mosquito A. Aegypti, e, por essa razão, iremos focar apenas nele.

3 Ao longo deste artigo, optamos por também usar o feminino para nos referirmos a alguma categoria mista de pessoas. Reconhecemos que essa solução corre o risco de reforçar binarismos de gênero, mas tentamos, ao menos, questionar a naturalidade com que o masculino é entendido como sendo o genérico da humanidade.

4 Criada pela então vice-presidente de ensino da Fiocruz, Nísia Trindade Lima, a rede visa a produzir pesquisas e respostas ao Zika Vírus, destacando e analisando não só os impactos sociais, políticos, econômicos e morais da epidemia, bem como o processo de produção de saberes científicos. Atualmente ela é coordenada por Gustavo Corrêa Matta, pesquisador da Fiocruz, e inclui pesquisadores de diversas instituições nacionais e internacionais.

5 Para um outro exemplo de antropologia do vírus, ver Lowe (2010).

6 Fundação filantrópica dos Rockefellers, família estadunidense cuja imensa fortuna cresceu dos lucros das indústrias de petróleo e bancária - ver Farley (2004).

7 Geralmente, só cientistas europeus e norte-americanos recebem crédito pela descoberta. Além do frequente apagamento do trabalho feito por técnicos e assistentes de pesquisa (HERZIG, 2005; SHAPIN, 1989), nesse caso, essa invisibilidade é também marcada pelas condições e implicações do colonialismo e da supremacia branca.

8 Durante a epidemia na Polinésia Francesa, pesquisadores indicaram a correlação entre Zika e o aumento do número de casos de Síndrome de Guillain-Barré, um distúrbio autoimune que afeta o sistema nervoso periférico (CAO-LORMEAU et al., 2016).

9 Além de mosquitos, a categoria arboviroses inclui doenças ocasionadas por vírus transmitidos por todos os artrópodes como, por exemplo, os carrapatos.

10 Para uma análise de animais não humanos e insetos vetores e hospedeiros transformados em "vilões epidêmicos", ver Lynteris (2019) e, para uma perspectiva sobre mosquitos como "mais que vetores", ver Maia $(2018 ; 2020)$.

${ }^{10}$ Esse neurotropismo estaria associado, também, aos casos de Síndrome de GuillainBarré (CAO-LORMEAU et al., 2016)

${ }^{11}$ Enquanto reconhecemos que as incertezas durante a epidemia, inclusive as várias vias de transmissão, criaram uma situação assustadora e que a (possibilidade) de infecção causou ansiedade e sofrimento para gestantes (MELLO; RONDON, 
2020), nós nos posicionamos veementemente contra narrativas capacitistas que descreviam (e descrevem) a SCZV em si, e deficiências em geral, como "assustadoras" (LUSTOSA; SAFATLE, 2019, p. 138; para um debate sobre capacitismo, deficiência e antropologia ver o dossiê RIOS; PEREIRA; MEINERZ, 2019).

12 Esforços pontuais de distribuição de repelentes, como parte do cuidado pré-natal do SUS, tiveram alcance limitado. Assim sendo, o acesso foi restrito àquelas que podiam arcar com os custos do produto. Vale destacar, ainda, que estudos apontam que o DEET, principal substância dos repelentes brasileiros, pode ser tóxico, inclusive para o feto. Além disso, é possível que o suor diminua o tempo de ação de alguns repelentes (RIBAS; CARREÑO, 2010). Agradecemos a Túllio Maio por mencionar a esses dados.

13 Para análises sobre narrativas imunológicas e as maneiras pelas quais "imunidade" é mobilizada como um capital biopolítico, marcado por diferenças de gênero e raça, ver Martin (1994) e Olivarius (2019).

14 Ao trazermos esse debate sobre cor/raça e expressões do racismo, enquanto sujeitas pouco ou não marcadas por tais vivências, reconhecemos e ressaltamos que pessoas posicionadas por suas "(escre)vivências" (EVARISTO, 2006) e atuações em movimentos negros devem seguir assumindo a centralidade nas contribuições ao campo científico e/ou político que lhes foi, histórica e violentamente, negada.

15 Um estudo sobre saúde e disparidades em termos de raça/cor demonstrou que, entre aquelas que tiveram o acesso à primeira maternidade negado, 18,5\% eram brancas, $28,8 \%$ pardas e $31,8 \%$ pretas (LEAL; GRANADO; BRAGA, 2005).

16 Caso o Culex seja também um vetor para Zika, a falta de saneamento possivelmente resultaria em uma discrepância ainda maior nas taxas de infecção em bairros mais pobres, já que esse mosquito prefere colocar seus ovos em criadouros com muita matéria orgânica em decomposição, como esgotos a céu aberto.

17 A relação entre as cianobactérias - micróbios presentes nos reservatórios de água em certas partes do Nordeste, que produzem uma neurotoxina, a saxitoxina (STX) - e o possível agravamento dos efeitos do Zika (PEDROSA et al., 2020), não apenas explicaria o maior número de casos de SCZV nessa região, mas também evidenciaria o complexo enredamento entre diferentes seres e substâncias, em corpos historicamente situados e marcados por desigualdades na produção da saúde.

\section{Referências}

ABRAMOWITZ, S. Epidemics (Especially Ebola). Annual Review of Anthropology, [S.l.], v. 46, p. 421-45, 2017.

ALBUQUERQUE, M. DE F. P. M. DE et al. Epidemia de microcefalia e vírus Zika: a construção do conhecimento em epidemiologia. Cadernos de Saude Publica, v. 34, p. $00069018,2018$.

ALBUQUERQUE, M. et al. Access to healthcare for children with Congenital Zika Syndrome in Brazil: perspectives of mothers and health professionals. Health Policy and Planning, [S.l.], v. 34, n. 7, p. 499-507, 2019.

ALLARD, A. et al. The risk of sustained sexual transmission of Zika is underestimated. PLoS Pathogens, [S.l.], v. 13, n. 9, p. el006633, 2017. 
ALMEIDA, S. Racismo Estrutural. São Paulo: Polen Livros, 2019.

ALMELING, R. Reproduction. Annual Review of Sociology, [S.l.], v. 41, p. 423-42, 2015.

ALVES, R. L. C.; FLEISCHER, S. R. O Que Adianta Conhecer Muita Gente e no Fim das Contas Estar Sempre só? Desafios da maternidade em tempos de Síndrome Congênita do Zika Vírus. Revista Anthropológicas, [S.l.], v. 29, n. 2, p. 6-27, 2018.

ANDERSON, W. Colonial Pathologies: American Tropical Medicine, Race, and Hygiene in the Philippines. Durham: Duke University Press, 2006.

ARAÚJO, C.; PERON, I. Ministro defende calça comprida para mulheres evitarem zika. Revista Exame, Brasília, 9 dez. 2015. Disponível em: https://exame.abril.com.br/brasil/ministro-recomenda-calca-compridapara-mulheres-evitarem-zika/. Acesso em: 12 jul. 2018.

ARAÚJO, T. de. Ministro da Saúde disse torcer para que mulheres peguem zika. Revista Exame, São Paulo, 14 jan. 2016. Disponível em: https:// exame.abril.com.br/brasil/ministro-da-saude-disse-torcer-para-quemulheres-peguem-zika/. Acesso em: 12 jul. 2018.

ASSIS, S. S. de; PIMENTA, D. N.; SCHALL, V. T. A Dengue nos Livros Didáticos de Ciências e Biologia Indicados pelo Programa Nacional do Livro Didático. Ciênc. Educ., [S.l.], v. 19, n. 3, p. 633-656, 2013.

BENCHIMOL, J. L. Dos Micróbios aos Mosquitos: febre amarela e a revolução pasteuriana no Brasil. Rio de Janeiro: Editora Fiocruz; Editora UFRJ, 1999.

BENTON, A.; SANGARAMOORTHY, T.; KALOFONOS, I. Temporality and Positive Living in the Age of HIV/AIDS. Current Anthropology, [S.l.], v. 58, n. 4, p. 454-476, 2017.

BORGES, A. L. V. et al. Women's reproductive health knowledge, attitudes and practices in relation to the Zika virus outbreak in northeast Brazil. PLoS ONE, [S.l.], v. 13, n. 1, p. e0190024, 2018.

BOSELEY, S. On the frontline in Brazil's war on Zika: 'I felt I was in a horror movie'. The Guardian, Recife, 12 abr. 2016. Disponível em: https:// www.theguardian.com/global-development/2016/apr/12/on-front-linebrazil-war-zika-virus-i-felt-horror-movie-no-cure. Acesso em: 15 mar. 2018.

BRASIL. Ministério da Saúde. CGSH/GGPBS/GGMON/ANVISA. Nota técnica conjunta 001: Critérios técnicos para o gerenciamento do risco sanitario no uso de hemocomponentes em procedimentos transfusionais frente à situação de Emergência em Saude Publica de Importância Nacional por casos de infecção por Zika Vírus no Brasil. Brasília, 22 dez. 2015. 
BRASIL. Ministério da Saúde. ANVISA/SAS. Nota técnica conjunta 002: Critérios técnicos para triagem clinica de candidatos à doação de sangue para os virus Zika e Chikungunya. Brasília, 19 ago. $2016 a$.

BRASIL. Ministério da Saúde. GSTCO/GGMED/DIARE/ANVISA. Nota técnica conjunta 008: Critérios técnicos para o gerenciamento do risco sanitário de células, tecidos germinativos e embriões humanos para uso terapêutico frente aos casos de infecção por virus Zika no Brasil. Brasília, 30 mar. 2016 b.

BRIDGES, K. M. Quasi-Colonial Bodies: An Analysis of the Reproductive Lives of Poor Black and Racially Subjugated Women. Columbia Journal of Gender and Law, [S.l.], v. 18, n. 2, p. 609-646, 2009.

BRIGGS, C. L.; MANTINI-BRIGGS, C. Stories in the Time of Cholera: Racial profiling during a medical nightmare. Berkeley: University of California Press, 2003.

BRITO, C. Zika Vírus. A New Chapter in the History of Medicine. Acta Med Port, [S.l.], v. 28, n. 6, p. 679-680, 2015.

BROWN, H.; KELLY, A. H. Material Proximities and Hotspots: Toward an Anthropology of Viral Hemorrhagic Fevers. Medical Anthropology Quarterly, [S.l.], v. 28, n. 2, p. 280-303, 2014.

BROWN, H.; NADING, A. M. Introduction : Human Animal Health in Medical. Medical Anthropology Quarterly, [S.l.], v. 33, n. 1, p. 5-23, 2019.

BURKE, S. D. A. Tuberculosis: Past and Present. Reviews in Anthropology, [S.l.], v. 40, n. 1, p. 27-52, 2011.

CABALION, S. et al. Middle East respiratory syndrome coronavirus and human-camel relationships in Qatar. Medicine Anthropology Theory, [S.l.], v. 5, n. 3, p. 177-194, 2018.

CALVET, G. et al. Detection and sequencing of Zika virus from amniotic fluid of fetuses with microcephaly in Brazil: a case study. The Lancet Infectious Diseases, [S.l.], v. 16, n. 6, p. 653-660, 2016.

CAMPOS, G. S.; BANDEIRA, A. C.; SARDI, S. I. Zika Virus Outbreak, Bahia, Brazil. Emerging Infectious Diseases, [S.l.], v. 21, n. 10, p. 1. 885-1.886, 2015.

CAMPOS, L. A. O Pardo Como Dilema Político. Insight Inteligência, [S.l.], v. 62, p. 80-91, 2013.

CAO-LORMEAU, V. M. et al. Guillain-Barré Syndrome outbreak associated with Zika virus infection in French Polynesia: A case-control study. The Lancet, [S.l.], v. 387, n. 10027, p. 1.531-1.539, 2016. 
CARNEIRO, R.; FLEISCHER, S. R. "Eu não esperava por isso. Foi um susto": conceber, gestar e parir em tempos de Zika à luz das mulheres de Recife, PE, Brasil. Interface - Comunicação, Saúde, Educação, [S.l.], v. 22, n. 66, p. 709-720, 2018.

CARRARA, S. Tributo a Vênus: a luta contra a sífilis no Brasil, da passagem do século até os anos 40. Rio de Janeiro: Editora Fiocruz, 1996.

CARVALHO, L. P. Vírus Zika e Direitos Reprodutivos: entre as políticas transnacionais, as nacionais e as ações locais. Cadernos de Gênero e Diversidade, [S.l.], v. 3, n. 2, p. 134-157, 2017.

CASTRO, A.; KHAWJA, Y.; JOHNSTON, J. Social Inequalities and Dengue Transmission in Latin America. In: HERRING, A.; SWEDLUND, A. (ed.).

Plagues and Epidemics: Infected Spaces Past and Present. New York: Berg, 2010. p. 231-249.

CHAKRABARTI, P. Imperialism and Tropical Medicine. In: CHAKRABARTI, P. Medicine and Empire: 1600-1960. London: Palgrave Macmillan, 2014. p. 141-163.

CHALHOUB, S. The Politics of Disease Control: Yellow Fever and Race in Nineteenth Century Rio de Janeiro. Journal of Latin American Studies, [S.l.], v. 25, n. 3, p. 441-463, 1993.

COELHO, F. C. et al. Higher incidence of Zika in adult women than adult men in Rio de Janeiro suggests a significant contribution of sexual transmission from men to women. International Journal of Infectious Disease, [S.l.], v. 51, p. 128-132, 2016.

COITINHO FILHO, R. A. O parentesco conformado na experiência soropositiva: uma abordagem antropológica sobre a transmissão vertical para o HIV na perspectiva crítica dos estudos de gênero. In: VI REUNIÃO DE ANTROPOlOGIA DA CIÊNCIA E DA TECNOLOGIA. Anais [...]. São Paulo: Instituto de Estudos Brasileiros, USP, 2017, p. 58-72.

COUTINHO, M. Tropical Medicine in Brazil: The Case of Chagas' Disease. In: DIEGO ARMUS (ed.). Disease in the History of Modern Latin America: from Malaria to AIDS. Durham: Duke University Press, 2003. p. 76-100.

CRADDOCK, S.; HINCHLIFFE, S. One world, one health? Social science engagements with the one health agenda. Social Science and Medicine, [S.l.], v. 129, p. 1-4, 2015.

CRENSHAW, K. Documento para o Encontro de Especialistas em Aspectos da Discriminação Racial Relaticos ao Gênero. Estudos Feministas, [S.l.], v. 10, n. 1, p. 171-188, 2002. 
CUMMISKEY, J. R. Placing Global Science in Africa: International Networks, Local Places, and Virus Research in Uganda, 1936-2000. 2017. 298 p. Tese (Doutorado em History of Medicine) - School of Medicine Johns Hopkins University, Baltimore, 2017.

CUMMISKEY, J. R. An Ecological Experiment on the Grand Scale: Creating an Experimental Field in Bwamba, Uganda, 1942-1950. Isis, [S.l.], v. 111 , n. 1, p. 3-21, 2020.

DELAPORTE, F. The History of Yellow Fever: An Essay on the Birth of Tropical Medicine. Tradução Arthur Goldhammer. Cambridge and London: MIT Press, 1991.

DICK, G. W. A.; KITCHEN, S. F.; HADDOW, A. J. Communications: Zika virus isolations and serological specificity. Transactions of the Royal

Society of Tropical Medicine and Hygiene, [S.l.], v. 46, n. 5, p. 509-520, 1952.

DINIZ, D. Zika: Do sertão nordestino à ameaça global. Rio de Janeiro: Civilização Brasileira, 2016.

DOUGLAS, M. Pureza e perigo: ensaio sobre a noção de poluição e tabu. Lisboa: Edições 70, 1991.

DUFFY, M. R. et al. Zika virus outbreak on Yap Island, Federated States of Micronesia. The New England Journal of Medicine, [S.l.], v. 360, n. 24, p. 2.536-2.543, 2009.

ETRINGER, A. et al. Reprodução humana assistida: análise de custo de um centro de alta complexidade para o Sistema Único de Saúde. Cadernos de Saúde Pública, [S.l.], 2020. No prelo.

EVARISTO, C. Beco das memórias. Belo Horizonte: Mazza, 2006.

FANON, F. The Wretched of the Earth. New York: Grove, 1963.

FARLEY, J. To Cast Out Disease: a History of the International Health Division of the Rockefeller Foundation (1913-1951). Oxford: Oxford University Press, 2004.

FARMER, P. AIDS and Accusation: Haiti and the Geography of Blame. Berkeley: University of California Press, 1992.

FERNANDES, C. Figuras do constrangimento: As instituições de Estado e as políticas de acusação sexual. MANA, [S.l.], v. 25, p. 365-390, 2019.

FONSECA, C. Apresentação - De família, reprodução e parentesco: algumas considerações. Cadernos Pagu, [S.l.], v. 29, p. 9-35, jul-dez. 2007. FOY, B. D. et al. Probable Non-Vector-borne Transmission of Zika Virus, Colorado, USA. Emerging Infectious Diseases, [S.l.], v. 17, n. 5, p. 1-7, 2011. 
GONÇALVES, H. D. Corpo Doente: estudo acerca da percepção corporal da tuberculose. In: DUARTE, L. F. D.; LEAL, O. F. (ed.). Doença, sofrimento, perturbação: perspectivas etnográficas. Rio de Janeiro: Editora Fiocruz, 1998. p. 105-117.

GONDIM, R. Meanings of Neglected Diseases in the Global Health agenda: the place of populations and territories. Ciência \& Saúde Coletiva, [S.l.], v. 23, n. 7, p. 2.291-2.302, 2018.

GUEDES, D. et al. Zika virus replication in the mosquito Culex quinquefasciatus in Brazil. Emerging Microbes \& Infections, [S.l.], v. e69, n. June, 2017.

HAMMONDS, E. Seeing AIDS: Race, Gender and Representation. In: MANLOWE, J.; GOLDSTEIN, N. (ed.). The Gender Politics of HIV/AIDS in Women: Perspectives on the Pandemic in the U.S. New York: New York University Press, 1997. p. 113-126.

HASENBALG, C. Discriminação e desigualdades raciais no Brasil. Belo Horizonte: Editora UFMG, 1979.

HAYNES, D. M. Imperial Medicine: Patrick Manson and the Conquest of Tropical Disease. Philadelphia: University of Pennsylvania Press, 2001.

HELMREICH, S. Waves: An anthropology of scientific things. In: THE 2014 LEWIS HENRY MORGAN LECTURE. Anais [...]. Rochester: University of Rochester, 2014.

HENDERSON, R. R.; BARDOSH, K. Counting Zika: insidious uncertainties and elusive epidemic facts. In: BARDOSH, K. Locating Zika: Social Change and Governance in an Age of Mosquito Pandemics. London: Routledge, 2020. p. 31-54.

HERZIG, R. M. Suffering for Science: Reason and Sacrifice in Modern America. New Brunswick: Rutgers University Press, 2005.

HILLS, S. L. et al. Center for Disease Control and Prevention. Transmission of Zika Virus Through Sexual Contact with Travelers to Areas of Ongoing Transmission - Continental United States. Morbidity and Mortality Weekly Report Transmission, [S.l.], v. 65, n. 8, p. 215-6. 2016.

HOWE, C. et al. Paradoxical Infrastructures: Ruins, Retrofit, and Risk. Science, Technology \& Human Values, [S.l.], v. 41, n. 3, p. 547-565, 2016.

JACKSON, Z. I. Becoming Human: Matter and Meaning in an Antiblack World. New York: NYU Press, 2020.

KECK, F.; LAKOFF, A. Preface: Sentinel Devices. Limn, [S.l.], v. 3, 2013. 
KELLY, A. H. et al. Uncertainty in Times of Medical Emergency: Knowledge gaps and structural ignorance during the Brazilian Zika crisis. Social

Science \& Medicine, [S.l.], v. 246C, p. 112787, 2020.

KELLY, A. H.; KECK, F.; LYNTERIS, C. (ed.). The Anthropology of Epidemics. London and New York: Routledge, 2019.

KIM, C. R. et al. Investigating the sexual transmission of Zika virus. Lancet Global Health, [S.l.], v. 6, n. 1, p. e24-e25, 2018.

LAINÉ, N. Elephant tuberculosis as a reverse zoonosis: Postcolonial scenes of compassion, conservation, and public health in Laos and France.

Medicine Anthropology Theory, [S.l.], v. 5, n. 3, p. 157-176, 2018.

LAMOREAUX, J. What if the Environment is a Person? Lineages of Epigenetic Science in a Toxic China. Cultural Anthropology, [S.l.], v. 31, n. 2, p. 188-214, 2016.

LARKIN, B. The Politics and Poetics of Infrastructure. Annual Review of Anthropology, [S.l.], v. 42, p. 327-343, 2013.

LATENDRESSE, G.; FOUNDS, S. The Fascinating and Complex Role of the Placenta in Pregnancy and Fetal Well-being. Journal of Midwifery $\boldsymbol{\sigma}$ Women's Health, [S.l.], v. 60, n. 4, p. 360-370, 2015.

LE MARCIS, F. Traiter les corps comme des fagots: Production sociale de l'indifférence en contexte Ebola (Guinée). Anthropologie \& Santé, [S.l.], v. 11, 2015.

LEAL, C.; GRANADO, S.; BRAGA, C. Desigualdades raciais, sociodemográficas e na assistência ao pré-natal e ao parto, 1999-2001. Revista de Saúde Pública, [S.l.], v. 39, n. 1, p. 100-107, 2005.

LINDENBAUM, S. Kuru, Prions, and Human Affairs: Thinking About Epidemics. Annual Review of Anthropology, [S.l.], v. 30, p. 363-85, 2001.

LOPES, G.; REIS-CASTRO, L. A Vector in the (Re)Making: A History of Aedes aegypti as Mosquitoes that Transmit Diseases in Brazil.

In: LYNTERIS, C. (ed.). Framing Animals as Epidemic Villains. London: Palgrave Macmillan, 2019. p. 147-175.

LOWE, C. Viral Clouds: Becoming H5N1 in Indonesia. Cultural Anthropology, [S.l.], v. 25, n. 4, p. 625-649, 13 nov. 2010.

LÖWY, I. Vírus, mosquitos e modernidade: a febre amarela no Brasil entre ciência e política. Tradução Irene Ernest Dias. Rio de Janeiro: Editora Fiocruz, 2006.

LÖWY, I. Zika no Brasil: história recente de uma epidemia. Rio de Janeiro: Editora Fiocruz, 2019. 
LUSTOSA, R.; SAFATLE, Y. Mães de Micro: Perspectivas e Desdobramentos sobre Cuidado no Contexto da Síndrome Congênita do Zika Vírus (SCZV) em Recife/PE. Áltera, [S.l.], v. 1, n. 8, p. 115-145, 2019.

LYNTERIS, C. Introduction: Infectious Animals and Epidemic Blame. In: LYNTERIS, C. (ed.). Framing Animals as Epidemic Villains. London: Palgrave Macmillan, 2019. p. 1-25.

MACPHAIL, T. The Viral Network: A Pathography of the HiNl Influenza Pandemic. Ithaca: Cornell University Press, 2014.

MAIA, T. D. DA S. Cada um com sua luta: uma etnografia da relação entre sertanejos e mosquitos no Alto Sertão Sergipano. 2018. 189 p. Dissertação (Mestrado em Antropologia Social) - Centro de Educação de Ciências Humanas, Universidade Federal de São Carlos, São Carlos, 2018.

MAIA, T. D. da S. The mosquito struggle: other-than-vector ecologies in a 'Zika-free' Brazilian sertão. Histórias de Zika Series. Somatosphere: Science, Medicine, and Anthropology, 2 mar. 2020. Disponível em http://somatosphere.net/2020/mosquito-struggle-zika.html/

MAIO, M. C.; SANTOS, R. V. Raça como questão: História, Ciência e Identidades no Brasil. Rio de Janeiro: Editora Fiocruz, 2010.

MARTIN, A.; HOLLOWAY, K. Something there is that doesn't love a wall: Histories of the placental barrier. Studies in History and Philosophy of Biological and Biomedical Sciences, [S.l.], v. 47, p. 300-310, 2014.

MARTIN, E. Flexible Bodies: The Role of Immunity in American Culture from the Days of Polio to the Age of AIDS. Boston: Beacon Press, 1994.

MAVHUNGA, C. C. Vermin Beings: On Pestiferous Animals and Human Game. Social Text, [S.l.], v. 29, n. 1, p. 151-176, 2011.

MELLO, A. G. de; RONDON, G. Feminism, disability, and reproductive autonomy: abortion in times of Zika in Brazil. Histórias de Zika Series.

Somatosphere: Science, Medicine, and Anthropology, 17 fev. 2020. Disponível em: http://somatosphere.net/2020/abortion-zika.html/. Acesso em: 18 fev. 2020.

MORAN-THOMAS, A. What is Communicable? Unaccounted Injuries and "Catching" Diabetes in an Illegible Epidemic. Cultural Anthropology, [S.l.], v. 34, n. 4, p. 471-502, 2019.

MORAN, M. H. Missing bodies and secret funerals: the production of safe and dignified burials in the Liberian Ebola crisis. Anthropological Quarterly (Spec. Issue: Producing Ebola), [S.l.], v. 90, n. 2, 2017.

MORENS, D. M.; FOLKERS, G. K.; FAUCI, A. S. Eastern Equine Encephalitis Virus -Another Emergent Arbovirus in the United States. New England Journal of Medicine, [S.l.], v. 381, p. 1.989-1.992, 2019. 
MUEHLENBEIN, M. P. Disease and Human/Animal Interactions. Annual Review of Anthropology, [S.l.], v. 45, p. 395-416, 2016.

MULLIGAN, K. et al. Is dengue a disease of poverty? A systematic review. Pathogens and Global Health, [S.l.], v. 109, n. 1, p. 10-18, 2015.

MUSSO, D.; NILLES, E. J.; CAO-LORMEAU, V.-M. Rapid spread of emerging Zika virus in the Pacific area. Clinical Microbiology and Infection, [S.l.], v. 20, n. 10, p. O595-O596, out. 2014.

NADING, A. M. Mosquito Trails Ecology, Health, and the Politics of Entanglement. Berkeley: University of California Press, 2014.

NELVO, R. V. O enredo das condenações: uma etnografia entre documentos e "justiça" acerca de casos de transmissão do HIV. Revista Idealogando, [S.l.], v. 1, n. 2, p. 102-121, 2017.

NICASTRI, E. et al. Persistent detection of Zika virus RNA in semen for six months after symptom onset in a traveller returning from Haiti to Italy, February 2016. Eurosurveillance, [S.l.], v. 21, n. 31, p. pii=30314, 2016.

NUNES, J. (ANAHATA). A complexidade do "pardo" e o não-lugar indígena. 3 set. 2019. Disponível em: https://medium.com/@desabafos/acomplexidade-do-pardo-e-o-não-lugar-indígena-a8ale172e2b0. Acesso em: 20 mar. 2020.

NUNES, J.; PIMENTA, D. N. A Epidemia de Zika e os Limites da Saúde Global. Lua Nova, [S.l.], v. 98, p. 21 1-46, 2016.

OLIVARIUS, K. Immunity, Capital, and Power in Antebellum New Orleans. American Historical Review, [S.l.], v. 2, n. April, p. 425-455, 2019.

OLIVEIRA, J. P. de. Pardos, Mestiços ou Caboclos: os índios nos censos nacionais no Brasil (1872-1980). Horizontes Antropológicos, [S.l.], v. 3, n. 6, p. 61-84, 1997.

OMS - ORGANIZAÇÃO MUNDIAL DA SAÚDE. One Health. 21 set. 2017. Disponível em: https://www.who.int/news-room/q-a-detail/one-health. Acesso em: 10 mar. 2020.

OSÓRIO, R. G. O Sistema Classificatório de "Cor ou Raça" do IBGE. Brasília: IPEA, 2003.

PACKARD, R. M. The Making of a Tropical Disease: a Short History of Malaria. Baltimore: Johns Hopkins University Press, 2007.

PEDROSA, C. S. G. et al. The cyanobacterial saxitoxin exacerbates neural cell death and brain malformations induced by Zika virus. PLoS Neglected Tropical Diseases, [S.l.], v. 14, n. 3, p. e0008060, 2020. 
PETRIBU, N. C. D. L. et al. Common findings on head computed tomography in neonates with confirmed congenital Zika syndrome. Radiol Bras, [S.l.], v. 51, n. 6, p. 366-371, 2018.

PIMENTA, D. O cuidado perigoso: tramas de afeto e risco na Serra Leoa. 2019. 351 p. Tese (Doutorado em Antropologia Social) - Faculdade de Filosofia, Letras e Ciências Humanas, Universidade de São Paulo, São Paulo, 2019.

PORTO, R. M.; MOURA, P. R. S. O Corpo Marcado: A construção do discurso midiático sobre Zika Vírus e Microcefalia. Cadernos de Gênero e Diversidade, [S.l.], v. 3, n. 2, p. 158-191, 2017.

PRADO, H. Ce que l'épidémie du virus Zika dévoile des droits reproductifs et sexuels au Brésil. Cahiers des Amériques latines, [S.l.], v. 88-89, n. 2-3, p. 79-96, 2018.

REAGAN, L. J. Dangerous Pregnancies: Mothers, Disabilities, and Abortion in Modern America. Berkeley: University of California Press, 2012.

REIS-CASTRO, L. Histórias de Zika/Histórias of Zika. Somatosphere: Science, Medicine and Anthropology, [S.l.], 2 dez. 2019. Disponível em: somatosphere.net/2019/historias-of-zika.html/. Acesso em: 3 dez. 2019.

REIS-CASTRO, L. Becoming Without: Rearing and Releasing Transgenic Mosquitoes in Brazil. In: RAPPAPORT STUDENT PRIZE PANEL ANTHROPOLOGY \& ENVIRONMENT SOCIETY. Anais [...]. Online American Anthropological Association, 2020.

RIBAS, J.; CARREÑO, A. M. Avaliação do uso de repelentes contra picada de mosquitos em militares na Bacia Amazônica in the Amazon Basin. An. Bras. Dermatol., [S.l.], v. 85, n. 1, p. 33-38, 2010.

RICHARDS, P.; MOKUWA, A. Village funerals and the spread of Ebola virus disease. Hot Spots - Ebola in Perspective. Fieldsights, [S.l.], 7 oct. 2014. Disponível em: https://culanth.org/fieldsights/village-funerals-andthe-spread-of-ebola-virus-disease. Acesso em: 17 mar. 2020.

RIOS, C.; PEREIRA, É. L.; MEINERZ, N. Apresentação: Perspectivas antropológicas sobre deficiência no Brasil. Anuário Antropológico, [S.l.], v. 44, n. 1, p. 29-42, 2019.

ROBERTS, D. Fatal Invention: How Science, Politics, and Big Business Re-create Race in the Twenty-first Century. New York: New Press, 2011.

ROOSTH, S.; SCHRADER, A. Feminist Theory Out of Science: Introduction. Differences: A Journal of Feminist Cultural Studies, [S.l.], v. 23, n. 3, p. 1, 2012 . 
SANGARAMOORTHY, T. Treating the numbers: HIV/AIDS surveillance, subjectivity, and risk. Medical anthropology, [S.l.], v. 31, n. 4, p. 292-309, jan. 2012.

\section{SCHUCMAN, L. V. Entre o "encardido", o "branco" e o}

"branquíssimo": Raça, hierarquia e poder na construção da branquitude paulistana. 2012. 122 p. Tese (Doutorado em Psicologia Social) - Instituto de Psicologia, Universidade de São Paulo, São Paulo, 2012.

SCOTT, R. P. et al. Itinerários terapêuticos, cuidados e atendimento na construção de ideias sobre maternidade e infância no contexto da Zika. Interface - Comunicação, Saúde, Educação, [S.l.], v. 22, n. 66, p. 673-684, 2018.

SEGATA, J. O Aedes aegypti e o digital. Horizontes Antropológicos, [S.l.], v. 23, n. 48, p. 19-48, 2017.

SHAPIN, S. The Invisible Technician. American Scientist, [S.l.], v. 77, n. 6, p. 554-563, 1989.

SHILTS, R. And the Band Played On. New York: St. Martin's Press, 1987.

SILVA, A. C. R. da; MATOS, S. S. de; QUADROS, M. T. de. Economia Política do Zika: Realçando relações entre Estado e cidadão. Revista Anthropológicas, [S.l.], v. 28, n. 1, p. 223-246, 2017.

SMITH, J.; TAYLOR, E. M.; KINGSLEY, P. One World-One Health and neglected zoonotic disease: Elimination, emergence and emergency in Uganda. Social Science and Medicine, [S.l.], v. 129, p. 12-19, 2015.

SODIKOFF, M. Zoonosis. Theorizing the Contemporary - Lexicon for an Anthropocene Yet Unseen. Fieldsights, [S.l.], 6 abr. 2016. Disponível em: https://culanth.org/fieldsights/zoonosis. Acesso em: 12 mar. 2020.

SONTAG, S. AIDS and Its Metaphors. New York: Farrar, Straus \& Giroux, 1989.

SOUZA, A. de. "Sexo é para amador, gravidez é para profissional", diz ministro sobre microcefalia. Jornal Extra, Brasília, 18 nov. 2015. Disponível em: https://extra.globo.com/noticias/saude-e-ciencia/ sexo-para-amador-gravidez-para-profissional-diz-ministro-sobremicrocefalia-18080803.html. Acesso em: 12 jul. 2018.

STASSEN, L. et al. Zika Virus in the Male Reproductive Tract. Viruses, [S.l.], v. 10, n. 198, 2018.

STEPAN, N. L. Picturing Tropical Nature. London: Reaktion Books, 2001. 
TIZIANO, A. L. S. Potencialidades e limites para o desenvolvimento de uma política de atenção em reprodução humana assistida no SUS. 2011.193 p. Tese (Doutorado em Saúde da Criança e da Mulher) - Instituto Fernandes Figueira, Fundação Oswaldo Cruz, Rio de Janeiro, 2011.

TREVISAN, J. S. O vírus, nosso irmão. In: TREVISAN, J. S. Devassos no Paraíso: a homossexualidade no Brasil, da colônia à atualidade. Rio de Janeiro: Record, 1986 [2000]. p. 515-520.

TRIUNFOL, M. A new mosquito-borne threat to pregnant women in Brazil: An apparent connection between the emergence of Zika virus and an unusual rise in microcephaly has alarmed Brazilian authorities. The Lancet, [S.l.], v. 16, n. 2, p. 156-157, 2016.

VALLE, C. G. do. Identidades, Doença e Organização Social: um Estudo das "Pessoas Vivendo com HIV e AIDS". Horizontes Antropológicos, [S.l.], v. 8, n. 17, p. 179-210, 2002.

WENHAM, C. et al. Gender mainstreaming as a pathway for sustainable arbovirus control in Latin America. PLoS Neglected Tropical Diseases, [S.l.], v. 14, n. 2, p. e0007954, 2020.

WERNECK, J. Nossos passos vêm de longe! Movimento de Mulheres Negras e Estratégias Políticas contra o Sexismo e o Racismo. In:

WERNECK, J. (ed.). Mulheres Negras: um olhar sobre as lutas sociais e as políticas públicas. Rio de Janeiro: Criola, 2008. p. 76-85.

WERNECK, J. Racismo institucional e saúde da população negra. Saúde e Sociedade, [S.l.], v. 25, n. 3, p. 535-549, 2016.

WILLIAMSON, K. E. Cuidado nos tempos de Zika: notas da pós-epidemia em Salvador (Bahia), Brasil. Interface - Comunicação, Saúde,

Educação, [S.l.], v. 22, n. 66, p. 685-696, 2018.

YATES-DOERR, E. Kinship: Bodily Betrayal in the Time of Epigenetics. In: MASCIA-LEES, F. E. (ed.). A Companion to the Anthropology of the Body and Embodiment. West Sussex: Wiley-Blackwell, 2011. p. 292-306.

ZARA, A. L. de S. A. et al. Estratégias de controle do Aedes aegypti: uma revisão. Epidemiol. Serv. Saúde, [S.l.], v. 25, n. 2, p. 391-404, 2016.

Recebido em 14/09/2019

Aceito em 10/06/2020 


\section{Luísa Reis-Castro}

Doutoranda no programa de História, Antropologia, Ciência, Tecnologia e Sociedade (HASTS) do Instituto de Tecnologia de Massachusetts (MIT), Estados Unidos. Mestre (MSc e MA) em Estudos Sociais da Ciência e da Tecnologia (STS) pela Universidade de Maastricht, na Holanda, e Bacharel em Ciências Sociais pela Universidade Federal de Minas Gerais (UFMG). Pesquisadora da Rede Zika Ciências Sociais, Fiocruz.

Endereço profissional: 77 Massachusetts Avenue - E51-098, Cambridge, M.A. Estados Unidos. CEP: 02139-4307.

E-mail: luisarc@mit.edu

\section{Carolina de Oliveira Nogueira}

Doutora em Antropologia pelo Programa de Pós-Graduação em Antropologia Social do Museu Nacional - Universidade Federal do Rio de Janeiro. Pesquisadora da Rede Zika e Ciências Sociais.

Endereço profissional: Avenida Brasil, n. 4.365, Manguinhos, Rio de Janeiro, RJ. CEP: 2 1040-900.

E-mail: rolcas.nogueira@gmail.com 